\title{
THE APPLICATION OF THE MULTI-DIMENSIONAL CARTESIAN SPACE IN THE GRAPHIC ANALYSIS OF THE U.S. GROSS DOMESTIC PRODUCT (GDP)
}

\author{
Mario Arturo Ruiz Estrada \\ Econographication Virtual Laboratory (EVL) \\ Kuala Lumpur, Malaysia \\ E-mail address: mario-ruiz@econographication.com \\ URL: http://www.econographication.com
}

\section{Introduction}

In MD-Cartesian space (see Ruiz, 2005) consists of five axes $\left(\left[X_{1}, X_{2}, X_{3}, X_{4}\right], Y\right)$, representing four independent variables " $X_{1}$ ", " $X_{2}$ ", " $X_{3}$ " and " $X_{4}$ " and one dependent variable "Y" respectively. Each " $X$ " variable $\left(X_{1}, X_{2}, X_{3}, X_{4}\right)$ and " $Y$ " variable has its individual axis that is a vertical line with both positive and negative values. The positive and negative values are represented by $\left(\left[\left(\mathrm{X}_{1},-\mathrm{X}_{1}\right),\left(\mathrm{X}_{2},-\mathrm{X}_{2}\right),\left(\mathrm{X}_{3},-\mathrm{X}_{3}\right)\left(\mathrm{X}_{4},-\mathrm{X}_{4}\right)\right],(\mathrm{Y},-\mathrm{Y})\right]$ on the MD-Cartesian plane (see Table 1).

In the case of 2-D and 3-D Cartesian plane, the individual variables can be anywhere along the vertical and horizontal axes; but in the case of MD-Cartesian space all variables $\left(\mathrm{X}_{\mathrm{i}}\right)$ and the " $\mathrm{Y}$ " variable are either on the positive side of respective axes together on the negative side of their respective axes together (see Figure 1). In other words, the values of all " $X_{i}$ " $\left(X_{1}, X_{2}, X_{3}, X_{4}\right)$ and " $Y$ " can change in different directions. Therefore, any change in some or all " $X_{i}$ " will affect " $Y$ " directly.

Representing the dependent variable, the fifth axis, "Y" is positioned in the center of the Graph (among the other four axes). "Y" has a positive value and negative value. It is the convergent point of all the other four axes $X_{1}, X_{2}, X_{3}$ and $X_{4}$. In other words, all " $X_{i}$ " axes converge at the "Y" axis. The result is a graph represented by a plane that can be reshaped into two cubes or one cube. 


\section{Literature Review: The Application of Graphs in Economics}

In the uses of graphs in economic analysis, so far we suggest two systems of graphs have been used: basic analytical graph system and complex analytical graph system. The basic analytical graph system was first used in the $19^{\text {th }}$ century. It started with Antoine Augustin Cournot's work, where mathematics began to be used in Economics. The basic analytical graph system consists of Utility Theory, General Equilibrium, Optimal of Pareto, Partial Equilibrium and Indifference Curves. These graphs were introduced by innovator economists: William Stanley Jevons, Leon Walras, Vilfredo Pareto, Alfred Marshall and Francis Ysidro Edgeowrth respectively (McClelland, 1975).

The complex analytical graph system has its origin in the $20^{\text {th }}$ century. It started with the introduction of sophisticated mathematics techniques in the development of new economic models. Calculus, trigonometry, geometry, statistical methods and forecasting methods are used in these graphs. Three dimension (3-D) graphs are also part of the complex analytical graphs system and are applied in economic research (AvondoBodino, 1967).

Using the complex analytical graph system were the following economic models: General equilibrium and Welfare Theory (John R. Hicks), IS-LM Curve (Alvin H. Hansen), Development of Economic Theory: Static and Dynamic Analysis, (Paul A. Samuelson), Econometrics (Lawrence R. Klein), Phillips Curve (Alban W. Phillips), Okun Law (Arthur M. Okun), Economic Growth Theory (Robert M. Solow), Game Theory (John F. Nash and John von Neumann), Introduction of Dynamic Models and Econometrics (Jan Tinbergen), Monetary Theory (Milton Friedman), Rational Expectations Theory (Robert J. Barro). The rapid development of complex analytical graph system was facilitated by high technology and sophisticated instruments of analysis such as the electronic calculator and the computer. The development of the instruments of analysis in economics took place in two stages. The first stage involved the "Basic Computational 
Instruments", where electronic calculators were used to compute basic mathematical expressions (e.g. long arithmetic operations, logarithm, exponents and squares). This took place between the 1950's and 1960's. The second stage of development took place in the middle of the 1980's. This is when high speed and high storage computers with sophisticated software were first used. Called "High Computational Instruments", such sophisticated software enables easy information management, application of difficult simulations as well as the creation of high resolution and 3-D graphs. These instruments contributed substantially to the development and research of economics.

Each of the basic graph analysis system and complex graph analysis system can be categorized according to functions or dimensions. In terms of functions, the graphs are either descriptive or analytical. In terms of dimensions, the graph can be either 2-D or 3-D. In descriptive graphs, arbitrary information is used to observe the effect of theories. Analytical graphs on the other hand are time-series graphs, cross-section graphs and scatter diagrams. In analytical graphs, statistical data is used to show trends and relationships between two or more variables, and hence the effects of economic phenomena resulting from trade policy, monetary policy, fiscal policy, economic growth and economic development. The analytical focus of the graphs is supported by the application of high computational instruments based on sophisticated hardware and software. Based on 500 papers published in recognized economic journals ${ }^{1}$ between 1940's and 2005 (JSTOR and ELSEVIER, 2005), it is observed that the common types of graphs applied in the study of social sciences, especially in economics, are 2-D and 3D graphs. MD-Cartesian space introduced in this chapter, however, is a multi-dimension

\footnotetext{
1 American Economic Review, Journal of Policy Modeling, Economic Literature, Economic Development, International Economics Review, World Bank Economic Review, Economic Integration Journal, Econometrica, Journal of Policy Modeling, Cambridge Journal of Economics, Journal of Economic Development, Journal of Economic Integration, Oxford Review of Economic Policy, Quarterly Journal of Economics and Economica.
} 
focus. It enables economists to analyze economic phenomena from multiple perspectives and facets in space and time.

\section{Comparison of 2-D Cartesian plane, 3-D Cartesian plane and MD- Cartesian Space}

2-D and 3-D Cartesian plane (see Figure 1) have the limitation of not being able to show the relationship of several variables at the same time. 2-D Cartesian plane shows the relationship between one independent variable " $X$ " and one dependent variable "Y". 3-D Cartesian plane $(X, Y, Z)$ shows the relationship between two independent variables $(\mathrm{X}, \mathrm{Y})$ and one dependent variable is " $\mathrm{Z}$ ". MD-Cartesian space with its five axes $\left(\left[\left(X_{1}, X_{2}, X_{3}, X_{4}\right), Y\right)\right]$ however, shows the relationship between four independent variables $\left(\left[\left(\mathrm{X}_{1},-\mathrm{X}_{1}\right),\left(\mathrm{X}_{2},-\mathrm{X}_{2}\right),\left(\mathrm{X}_{3},-\mathrm{X}_{3}\right),\left(\mathrm{X}_{4},-\mathrm{X}_{4}\right)\right]\right.$ simultaneously and one dependent variable $(\mathrm{Y},-\mathrm{Y})$ (see Table 1).

In the case of 2-D and 3-D Cartesian planes, only the positive axes can be used by economists to analyze changes in some economic phenomenal (resulting from inflation, economic growth, Unemployment). In the case of MD-Cartesian space, both positive and negative axes can be used to observe any economic changes. 
Table 1:

Difference between 2-D, 3-D and MD Cartesian Space

\begin{tabular}{|c|c|c|c|}
\hline DIMENSION & AXIS & VARIABLES & VALUES \\
\hline $\begin{array}{c}\text { 2-DIMENSIONAL } \\
\text { Cartesian plane } \\
\text { 2-D }\end{array}$ & 2 Axes $(x, y)$ & $\begin{array}{c}1 \text { Dependent }(Y) \\
1 \text { Independent }(X)\end{array}$ & $(x, y) \&(-x,-y)$ \\
\hline $\begin{array}{c}\text { 3-DIMENSIONAL } \\
\text { Cartesian plane } \\
\text { 3-D }\end{array}$ & 3 Axes $(x, y, z)$ & $\begin{array}{c}1 \text { Dependent }(Z) \\
2 \text { Independent }(X, Y)\end{array}$ & $(x, y, z) \&(-x,-y,-z)$ \\
\hline $\begin{array}{l}\text { DIMENSIONAL } \\
\text { Cartesian Space } \\
\text { MD }\end{array}$ & $\begin{array}{c}5 \text { Axes } \\
\left(\left[\mathrm{x}_{1}, \mathrm{x}_{2}, \mathrm{x}_{3}, \mathrm{x}_{4}\right], \mathrm{y}\right)\end{array}$ & $\begin{array}{c}1 \text { Dependent }(Y) \\
4 \text { Independent } \\
\left(\mathrm{X}_{1}, \mathrm{X}_{2}, \mathrm{X}_{3}, \mathrm{X}_{4}\right)\end{array}$ & $\begin{array}{c}\left(\left[\mathrm{x}_{1}, \mathrm{x}_{2}, \mathrm{x}_{3}, \mathrm{x}_{4}\right], \mathrm{y}\right) \\
\& \\
\left(\left[-\mathrm{x}_{1},-\mathrm{x}_{2},-\mathrm{x}_{3},-\mathrm{x}_{4}\right],-\mathrm{y}\right)\end{array}$ \\
\hline
\end{tabular}

Source: Designed by the Author 
Figure 1

The 2-D, 3-D and Multi-Dimensional Cartesian Space (MD-Cartesian Space)

(a.) 2-D Cartesian plane

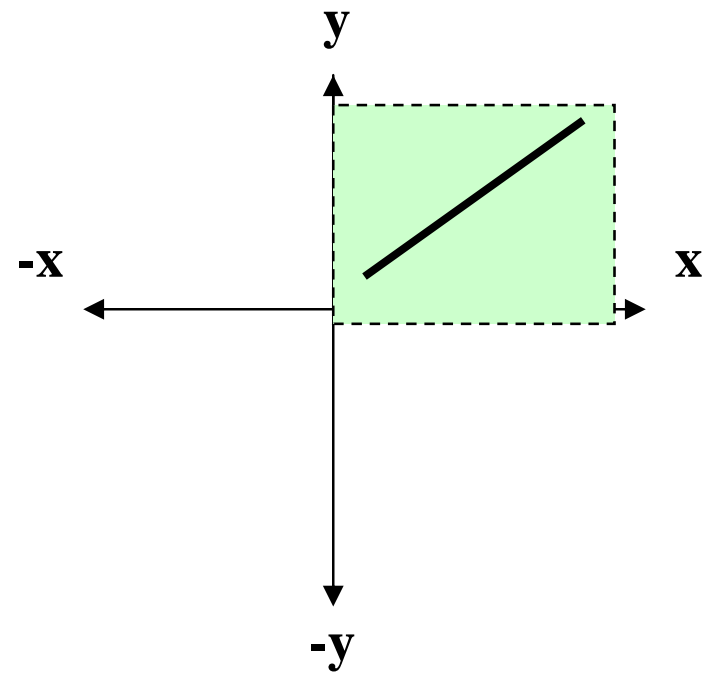

(b.) 3-D Cartesian plane

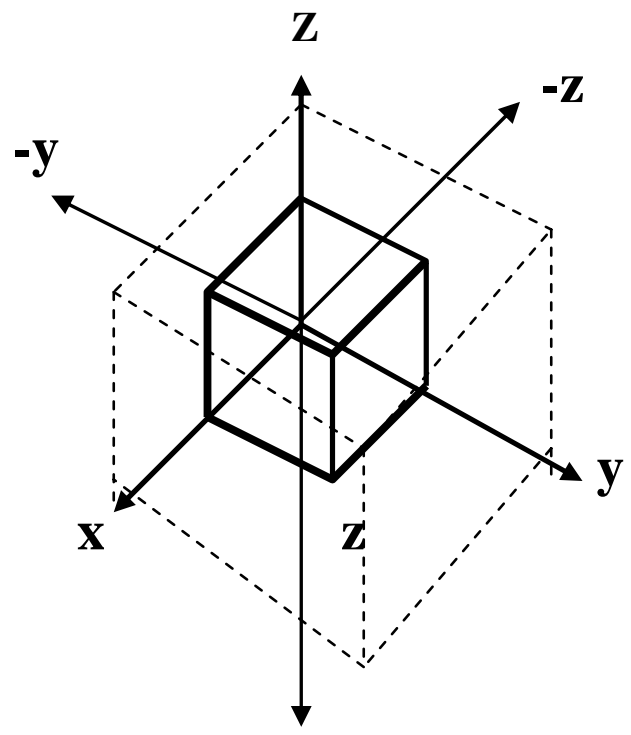

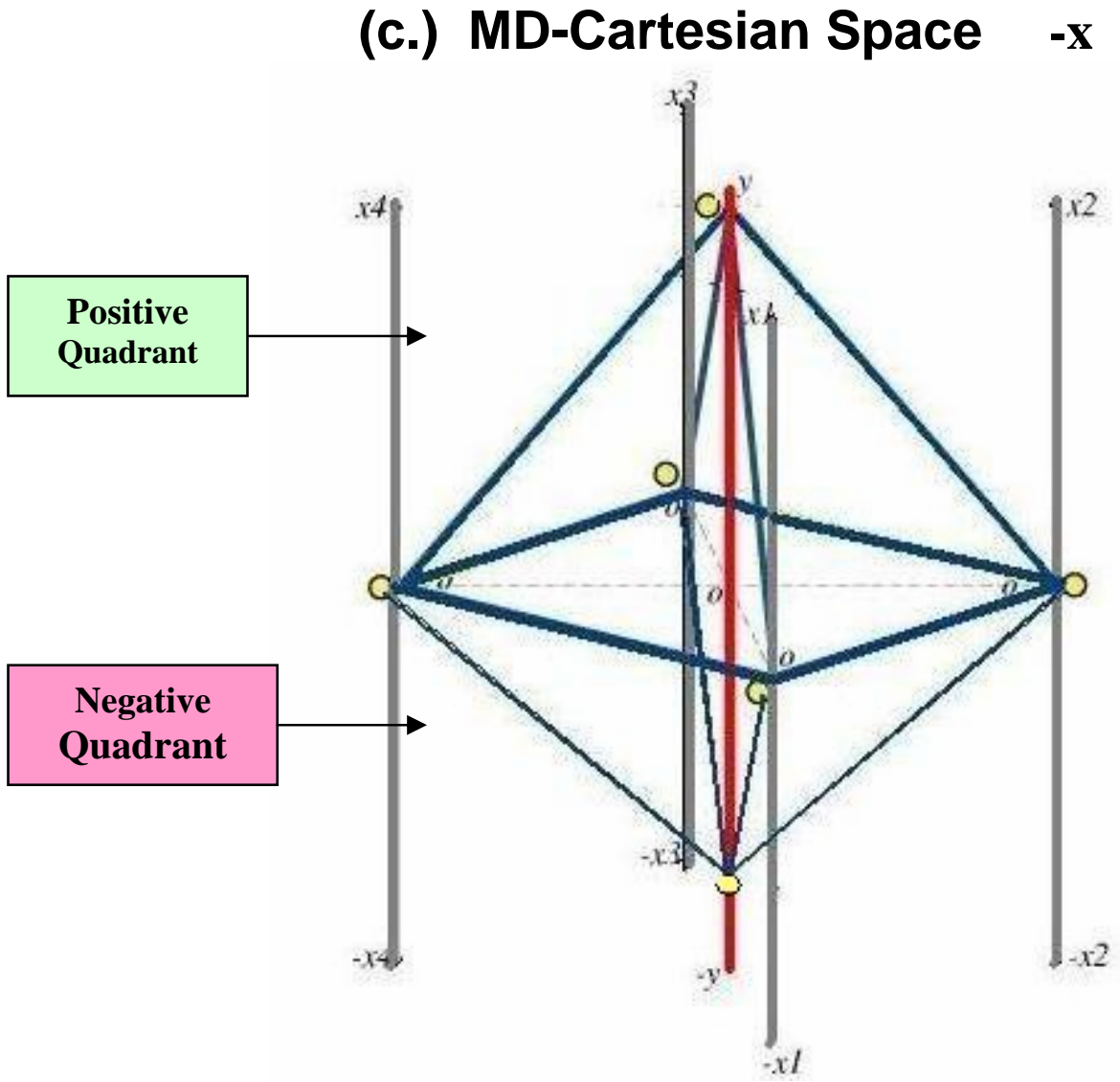

Source: Econographication Virtual Laboratory -EVL- 두 2005-2006 


\section{Application of the Multi-Dimensional Cartesian plane (MD-Cartesian Space)}

In this study, the application of MD-Cartesian space is demonstrated by its use in finding the national income "Y" accounts divide GDP into four broad categories of spending. In particular, the GDP is the sum of consumption, investments, government and net trade, represented by " $C=X_{1} ", " I=X_{2} ", " G=X_{3} "$ and "NT $=(X-M)=X_{4}$ " respectively in the expressions below. In the Figure 1, these four broad categories of spending of GDP are independent variables represented by $X_{1}, X_{2}, X_{3}$ and $X_{4}$ respectively, while the national income is represented by "Y". For demonstration purposes, the following data are used: U.S. consumption (C); investment (I); government (G); net trade (X-M) from 1989 to 2004 (see Figure 2). Steps involved in the application of MD-Cartesian space are as follows.

First step - to define national income: Expression (1)

$$
\text { (1.) } \mathrm{Y}=\mathrm{GDP}=\mathrm{C}+\mathrm{I}+\mathrm{G}+(\mathrm{X}-\mathrm{M}) \text {. }
$$

Second step - The construction of the "GDP Kite" is based on join GDP (Y) and the four broad categories of spending of $C=X_{1}, I=X_{2}, G=X_{3}$ and NT $=X_{4}$. We assume that join C, I, G, NT is not meaning of relationship or interdependency. We join all the four broad categories of spending ( $\mathrm{C}, \mathrm{I}, \mathrm{G}$ and NT) plus the GDP to build the "GDP Kite" to study the behavior of all economy from a global perspective. 
Third Step - GDP Kite Classification

Level 1: Good Performance

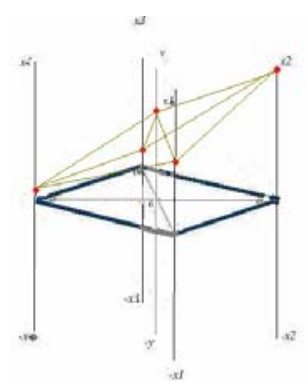

The GDP Kite is located in the positive quadrant

Level 2: Irregular Performance

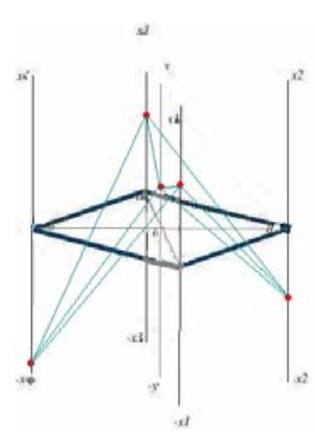

The GDP Kite is located between the positive and negative quadrant

Level 3: Poor Performance

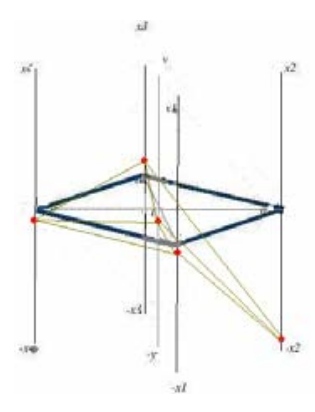

The GDP Kite is located in the negative quadrant or closed to 0 
The MD-Cartesian Space shows the national income from new visual perspective. This feature in MD-Cartesian space shows the multi-dimensional view of the national income to observe the movement of one or all variables $\left(X_{1}, X_{2}, X_{3}, X_{4}\right)$ along with their respective axes simultaneously on the same Cartesian space. It also shows how changes in one or all " $\mathrm{X}_{i}$ " can affect " $Y$ ". We applied MD-Cartesian Space on the study of the Gross Domestic Product (GDP) of U.S. from 1989 to 2004 (see Figure 2). The MD-Cartesian Space can show how U.S. Consumption (C), Investment (I), Government (G) and Net Trade (X-M) are moving in different directions simultaneously into the same Cartesian Space, in the same Cartesian Space is possible to visualized the U.S. GDP Kite. If we observe the U.S. GDP Kite year by year (from 1989 to 2004), the GDP shaves shows different displacements into the MD-Cartesian Spaces. From 1989 to 2004 , the U.S.-GDP Kite is located in the Level 1 or good performance (1989, 1992, 1995 and 1996). The level 1 or good performance is characterized by the positive results in all four broad categories of spending (C, I, G and NT) and GDP. The rest of year (1990, 1991, 1993,1994, 1997,1998,1999, 2000, 2001, 2002, 2003 and 2004) in this study shows level 2 or irregular performance, this level is characterized by non proportional results, it can be positive and negative values (see Figure 2).

If we generate a successive slide show based on the use of each GDP Kite by year then we can observe how the GDP Kite maintain a constant movement in the same MD-Cartesian Space. The advantage to use MD-Cartesian Space is based on large and constant storage of data and dynamic visualization of any economic phenomenon. 
Figure 2:

United States GDP Kite from 1989 to 2004

GDP/U.S.-1989: L1 GDP/U.S.-1990: L2 GDP/U.S.-1991: L2 GDP/U.S.-1992: L1
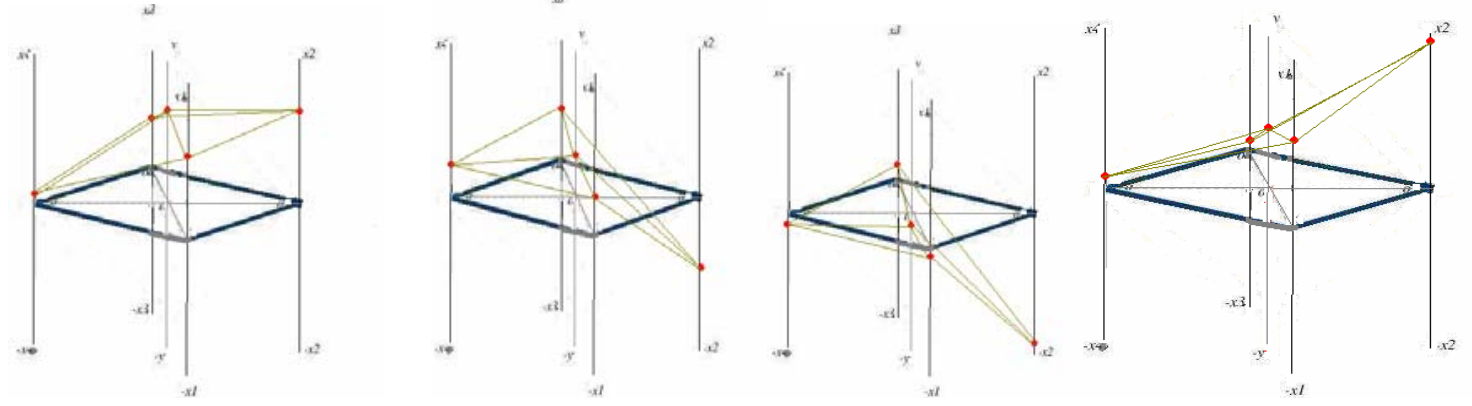

GDP/U.S.-1993: L2 GDP/U.S.-1994: L2 GDP/U.S.-1995: L1 GDP/U.S.-1996: L1

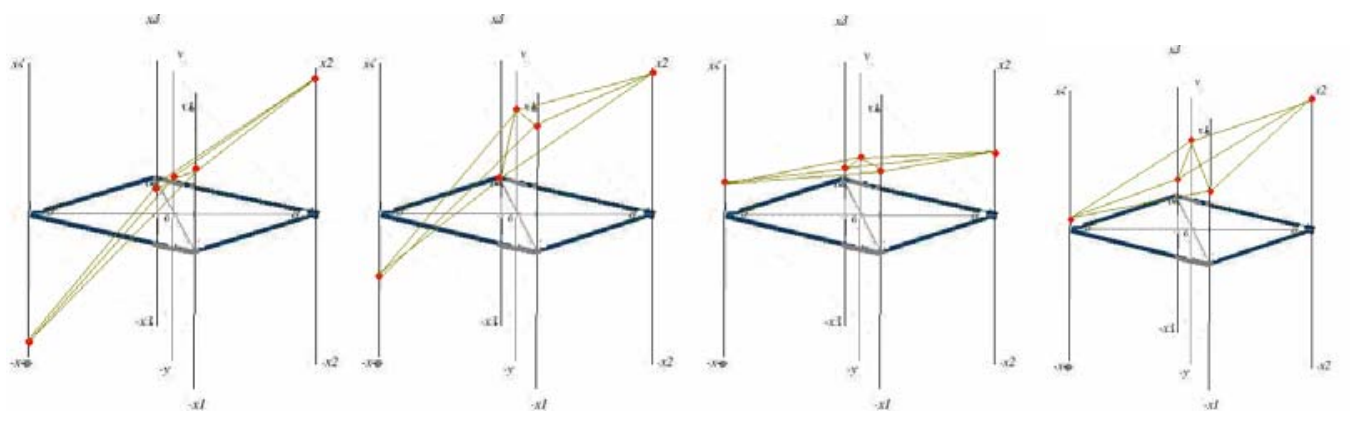

GDP/U.S.-1997: L2 GDP/U.S.-1998: L2 GDP/U.S.-1999: L2 GDP/U.S.-2000: L2
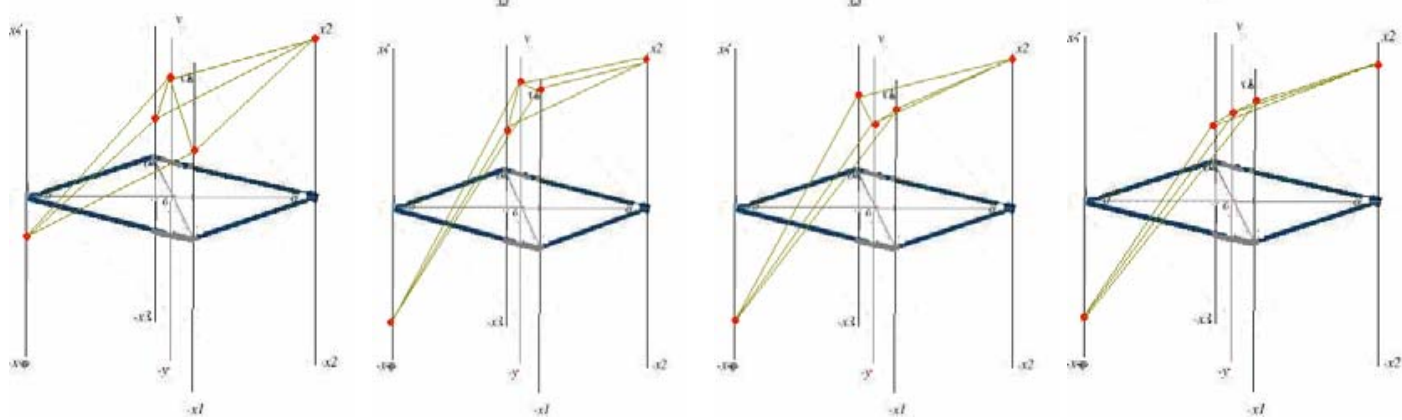

GDP/U.S.-2001: L2

GDP/U.S.-2002: L2 GDP/U.S.-2003: L2 GDP/U.S.-2004: L2
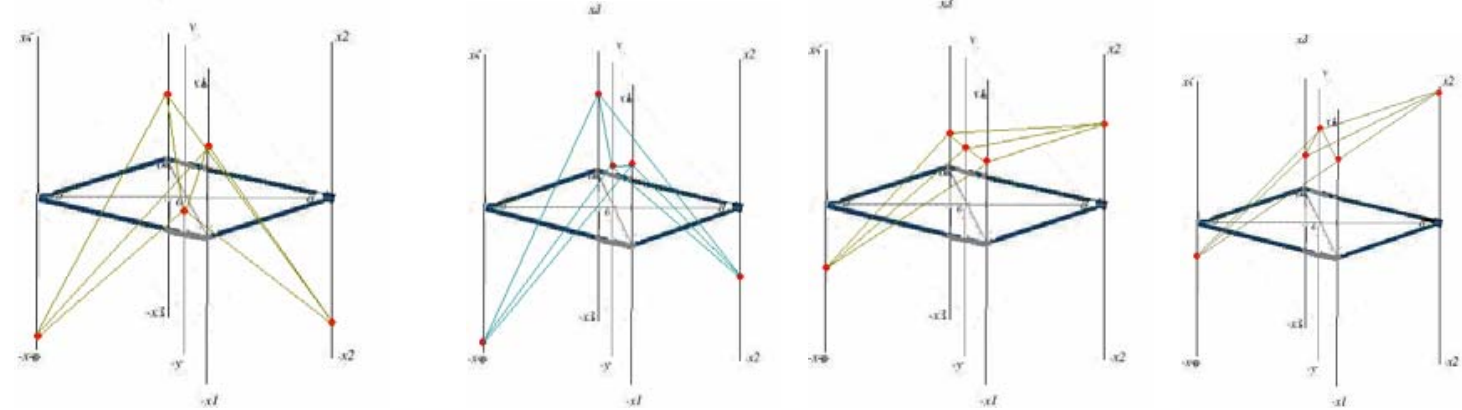

Source: Bureau of Economic Analysis U.S. Department of Commerce (2005) 


\section{Conclusion}

The Multi-Dimension Cartesian Space (MD-Cartesian Space) is a different analytical tool compared to the conventional 2-D and 3-D Cartesian planes. The MD shows the global context of any economic phenomena; Hence it allows for Macro-Microeconomics focus of analysis in economics. It is an efficient analytical tool to explain complex economic phenomena from a global perspective. It is obvious that the new Cartesian Space in this thesis is a better tool to visualize the correlation between the independent variables $\left(X_{1}, X_{2}, X_{3}\right.$ and $\left.X_{4}\right)$ and dependent variable (Y). As such, the MD-Cartesian Space provides a good alternative basis to design new types of graphs in economics.

\section{References}

Avondo-Bodino, G. (1963). Economic Applications of the Theory of Graphs, Gordon \& Breach Publishing Group, pp. 126

Bureau of Economic Analysis U.S. Department of Commerce (2005). GDP: Third Quarter 2005 (Final) Corporate Profits: Third Quarter 2005 (Final). Volume BEA 05-57

Elsevier (2005). Journal of Economics Section. http://www.elsevier.com

EVL (2006). Introduction to Econographicaiton, Econographication Virtual Laboratory (EVL), http://www.econographication.com , Publications Section.

JSTOR (2005). Journals in Economics Section. http://www.jstor.org

Ruiz, M. (2005). "New Visual Perspective for Economic Analysis: The Multi-dimensional Cartesian Plane", Working Papers FEA, 2005-1, pp. 1-15.

McClelland, P.D. (1975). Causal Explanation and Model Building in History, Economics, and the New Economic History, Cornell University Press, pp. 296 